\title{
Oligosaccharide Chitosan: Viscosity, Molecular Weight, Antibacterial Activity, and Impact of Y Radiation
}

\author{
Vu Ngoc Boi ${ }^{1,}$,, Nguyen Thi My Trang ${ }^{1}$, Dang Xuan Cuong ${ }^{2}$, Vu Thi Hoan ${ }^{3}$, Le Hai ${ }^{4}$ \\ ${ }^{1}$ Faculty of Food Technology, Nha Trang University, Nha Trang, Vietnam \\ ${ }^{2}$ Organic Matterial from Marine Resource, Nhatrang Institute of Technology Application and Research, Vietnam Academy of Science and \\ Technology (VAST), Ha Noi, Vietnam \\ ${ }^{3}$ Institute of Biotechnology and Food, Industrial University of Ho Chi Minh City, Ho Chi Minh, Vietnam \\ ${ }^{4}$ Da Lat Nuclear Research Institute, Vietnam Atomic Energy Insitute, Da Lat, Vietnam
}

\section{Email address:}

minhboint@yahoo.com(Vu N. Boi), trangntm@ntu.edu.vn (N. T. My Trang), cuong_mails@yahoo.com.vn (D. X. Cuong), yenhoan08@yahoo.com (Vu T. Hoan), lehaicnbx@yahoo.com (Le Hai)

${ }^{*}$ Corresponding author

\section{To cite this article:}

Vu Ngoc Boi, Nguyen Thi My Trang, Dang Xuan Cuong, Vu Thi Hoan, Le Hai. Oligosaccharide Chitosan: Viscosity, Molecular Weight, Antibacterial Activity, and Impact of $\gamma$ Radiation. World Journal of Food Science and Technology. Special Issue: Marine Bio-Polymer: Bio-Activity, Extraction and Application. Vol. 4, No. 2, 2020, pp. 40-45. doi: 10.11648/j.wjfst.20200402.14

Received: March 17, 2020; Accepted: March 30, 2020; Published: April 29, 2020

\begin{abstract}
Chitosan is a bioactive polymer produced from shrimp and crab shells, etc. According to VASEP (Vietnam Association of Seafood Exporters and Producers), the production of raw shrimp cultured in Vietnam was about 800,000 tons in 2018. Therefore, the shrimp processing industry has generated about 320,000 tons of wastes, including heads and shells. If wastes are not utilized and managed in proper ways, it can lead to serious environmental problems. In our study, shrimp shells were used to produce chitosan and further obtained oligochitosan for application in food preservation. The cobalt-60 radiation technology has been used to segment chitosan into oligochitosan. The radiation dose applied to chitosan solution was in the range of $25 \div 50 \mathrm{kGy}$ and in the range of $66 \div 166 \mathrm{kGy}$ for chitosan flakes. The results showed that the chitosan solution had higher segmental efficiency compared to that of chitosan flakes. The antibacterial activities of oligosaccharide chitosan segmented from chitosan flakes were higher than those of oligosaccharide chitosan segmented from chitosan solution. The highest antibacterial activities were observed in the oligochitosan segmented from chitosan flakes at the radiation dose of $66 \mathrm{kGy}$ for all tested bacteria: E. coli O157:H7, Salmonella typhimurium, Listeria monocytogenes, Staphylococcus aureus, Bacillus subtilis. In addition, oligochitosan segmented from chitosan flakes at the radiation dose of $66 \mathrm{kGy}$ had higher antibacterial activities on bacteria gram (-) than bacteria gram (+). The strongest antibacterial activities on L. monocytogenes and B. subtilis at the concentration of $0.3125 \%$.
\end{abstract}

Keywords: Radiation, Chitosan, Oligochitosan, Antibacterial, Bacteria Gram (-), Bacteria Gram (+)

\section{Introduction}

Chitosan is a biological polymer produced from shrimp and crab shells, etc [1-3]. Oligochitosan can be segmented from chitosan by using different technologies such as enzyme technology or cobalt-60 radiation technology [3-6]. Oligochitosan is believed to have antibacterial activities. Therefore, some researches have been carried out on using oligosaccharide chitosan in vegetable preservation and antifungal, etc [7-10]. The advantage of using cobalt-60 radiation technology to segment chitosan is that after segmentation oligochitosan products can be used immediately in the preservation process without purification or removal of impurities.

The aim of this study was to the impact of cobalt- 60 radiation on the viscosity, the molecular weight, and antibacterial activity of oligosaccharide chitosan. 


\section{Material and Methods}

\subsection{Material}

+ Chitosan: Chitosan was whiteness, fine flakes, $0.51 \%$ of protein, $0.5 \%$ of ash, the water content of $13.2 \%$, deacetyl degree of $93.5 \%$, soluble degree of $99.5 \%$, the viscosity of $1050 \mathrm{cPs}$, and turbidity of (NTU) 12.1 .

+ Bacteria strains: The bacteria strains were used for the antibacterial evaluation consisting of E. coli O157:H7, Salmonella typhimurium, Listeria monocytogenes, Staphylococcus aureus, and Bacillus subtilis that supplied by the Institute of Veterinary Research and Development of Central Vietnam.

The chemicals in the analysis were purchased from SigmaAldrich, except for distilled water and $96 \%$ ethanol of Vietnam.

\subsection{Methodologies}

The segment chitosan flakes and chitosan solution in $1 \%$ acetic acid were by using gamma $60 \mathrm{Co}$ radiation equipment (GC-5000) (Made in India) at the Da Lat Nuclear Research Institute. Radioactivity used was at $4.000 \mathrm{Ci}$, dose rate of $\sim 3,6$ $\mathrm{kGy} /$ hour, operating in semi-automatic mechanism. Radiation chamber volume of 4.4 liters. The radiation temperature was controlled by water at temperature of $25^{\circ} \mathrm{C}$ [10].

The irradiation of chitosan flakes and chitosan solutions was by various doses for collecting oligosaccharide chitosan, for example, 10, 30, 70, $166 \mathrm{kGy}$ for chitosan flakes and 10, $15,20,25$ and $50 \mathrm{kGy}$ for chitosan solutions. After the irradiation, all samples were filtered, segmented by different solvents (methanol and acetone), and evaluated on its viscosity and molecular weight.

The irradiation of chitosan solution and chitosan flakes was at $50 \mathrm{kGy}$ and by various doses $(66 \mathrm{kGy}, 76 \mathrm{kGy}, 100 \mathrm{kGy}, 158$ $\mathrm{kGy}$, and $166 \mathrm{kGy}$ ), respectively, for collecting the solution of antibacterial oligosaccharide chitosan that evaluated by using the method of minimum inhibitory concentration (MIC).

The molecular weight determination of chitosan and oligosaccharide chitosan was on the viscometer Ubbelohde [11]. The determination of solution viscosity was on the machine.

Segment separation was by using specific solvents [10].

Antibacterial activities determination of oligosaccharide chitosan was by using the method of minimum inhibitory concentration (MIC), as in $[12,13]$. Results assessment: The evaluation of antibacterial activity was according to the following levels: ++++: 100\% inhibition (non-presented bacteria colonies); +++: inhibition from $75 \%$ to $<100 \%$; ++: inhibition from 50 to $<75 \%$; + : inhibition from 25 to $<50 \%$; (-): negative, and positive evaluation in levels +++ and ++++ .

\subsection{Data Analysis}

The data sets presented were mean of three different replicates. Means were calculated and graphed by using MS. Excel 2007 software.

\section{Results and Discussion}

\subsection{The Viscosity}

When the radiation dose increased, the viscosity was decreased for chitosan solution preparing from chitosan of flakes and solution. The solution viscositiy of flakes chitosan was higher than one of solution chitosan. The concentration of chitosan also decided the viscosity of the radiated chitosan concentration. The concentration of chitosan flakes affected the viscosity of soluton more than chitosan solution, as in Figures 1 and 2 .

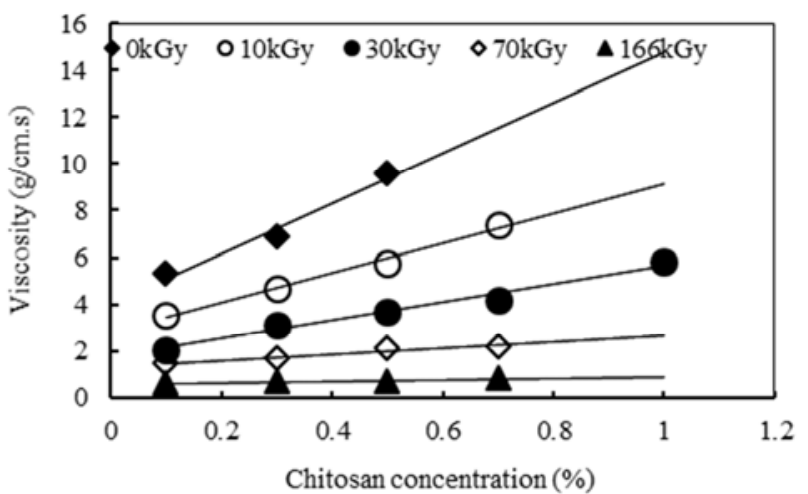

Figure 1. The viscosity of solution preparing from chitosan flakes according to chitosan concentration and radiation dose.

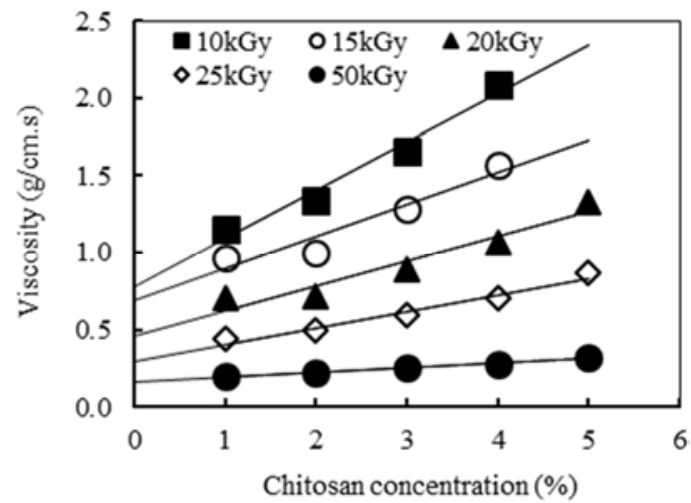

Figure 2. The viscosity of solution preparing from chitosan solution according to chitosan concentration and radiation dose.

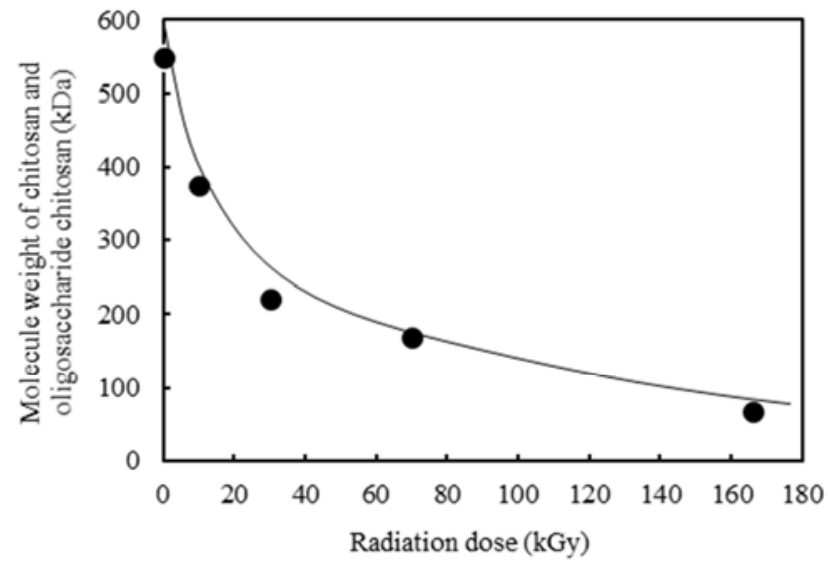

Figure 3. The molecular weight of chitosan oligosaccharide chitosan preparing from chitosan flakes according to the radiation dose. 


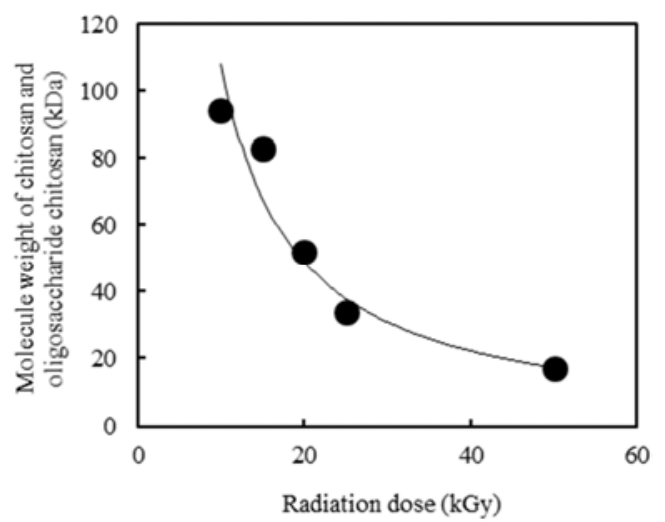

Figure 4. The molecular weight of chitosan and oligosaccharide chitosan preparing from chitosan solution according to the radiation dose.

\subsection{The Molecule Weight}

The radiation dose affected the weight molecular of chitosan $(p<0.05)$. The molecular weight of chitosan decreased with increasing the radiation dose for both chitosan flakes and chitosan solution (Figures 3 and 4, respectively). The molecular weight of chitosan flakes decreased from about $549 \mathrm{kDa}$ to $67 \mathrm{kDa}$ (decreasing 8.2 times) at the radiation dose of $166 \mathrm{kG} \gamma$ (Figure 3). It means that chitosan had segmented into smaller molecular weight chitosan (called oligosaccharide chitosan) and similar to those notices of Ulanski et al. (1992) [14] and Le Hai et al. (2003) [10]. After radiation, the molecular weight was $94 \mathrm{kDa}$ at the radiation dose of $10 \mathrm{kGy}$, which decreased 5.8 times compared to the control sample. At radiation dose of $15 \mathrm{kGy}, 20 \mathrm{kGy}, 25 \mathrm{kGy}$, and $50 \mathrm{kGy}$, the molecular weight of chitosan corresponded about $83 \mathrm{kDa}, 52 \mathrm{kDa}, 34 \mathrm{kDa}$, and $17 \mathrm{kDa}$, respectively, for solution chitosan (Figure 4). It means the $\gamma 60$ radiation segmented chitosan in forms of either chitosan flakes or chitosan solution. The $\gamma 60$ radiation impacted on solution chitosan more than chitosan flakes.

Oligosaccharide chitosan in solution was continuously precipitated in different solvents, for example, methanol and acetone. The results showed acetone precipitated the lowest oligosaccharide chitosan of the molecular weight and the content, compared to methanol solvent. The molecular weight of oligosaccharide chitosan was arranged in the increasing order for a molecular weight as follows: acetone, the methanol to chitosan solution ratio $(9 / 1(\mathrm{v} / \mathrm{v}))$, and the methanol to chitosan solution ratio $(2 / 1(\mathrm{v} / \mathrm{v}))$. The average molecular weight was in the range of $15-70 \mathrm{kDa}$ for the $1^{\text {st }}$ segment 1 and $11-50 \mathrm{kDa}$ for the $2 \mathrm{nd}$ segment. The average molecular weight of 3rd segment was under $11 \mathrm{kDa}$ (Figures 5 and 6). The content of oligosaccharide chitosan in the precipitation segment by using the methanol to chitosan solution ratio $(2 / 1$ $(\mathrm{v} / \mathrm{v}))$ was 40 and 1.8 times, compared to the precipitation segment by using acetone and the methanol to chitosan solution ratio $(9 / 1(\mathrm{v} / \mathrm{v}))$, respectively. The oligosaccharide chitosan in $1^{\text {st }}, 2^{\text {nd }}$, and $3^{\text {rd }}$ segment was black color, gelatinous form, and ivory-white color powder, respectively. The oligosaccharide chitosan in the $3^{\text {rd }}$ segment solubilized well in water with a molecular weight under $11 \mathrm{kDa}$. The solution viscosity was a positive correlation to the chitosan concentration and a negative correlation to radiation dose for both chitosan flakes and chitosan solution.

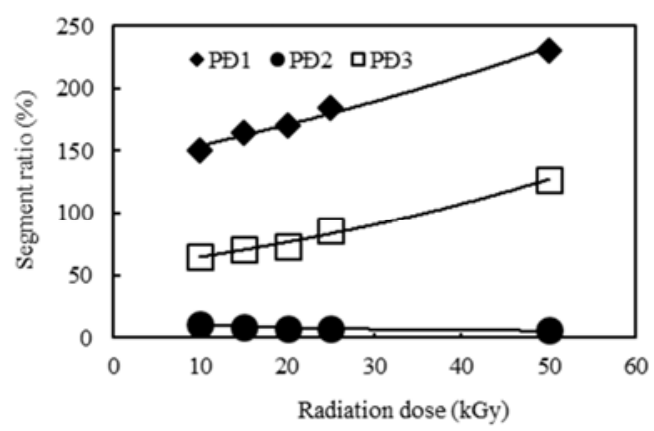

Note: $\mathrm{PĐ}_{\mathrm{i}}$ : Segment i, and i was from 1 to 3.

Figure 5. Changes in segment ratio of oligochitosan as a function of radiation dose (chitosan solution).

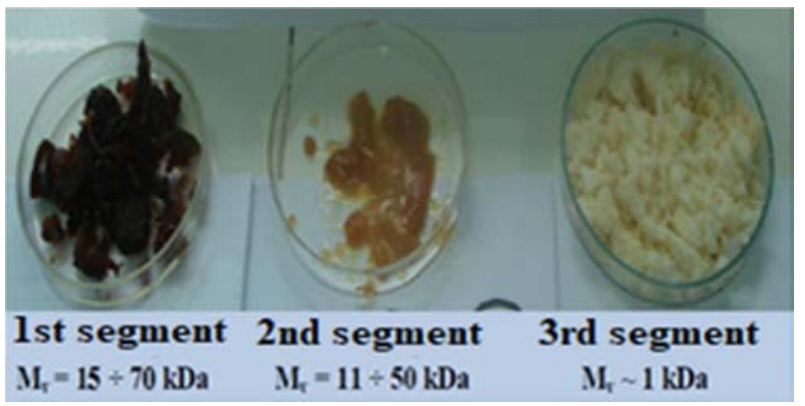

Figure 6. Pictures of different segments of oligochitosan at the radiation dose of $50 \mathrm{kGy}$.

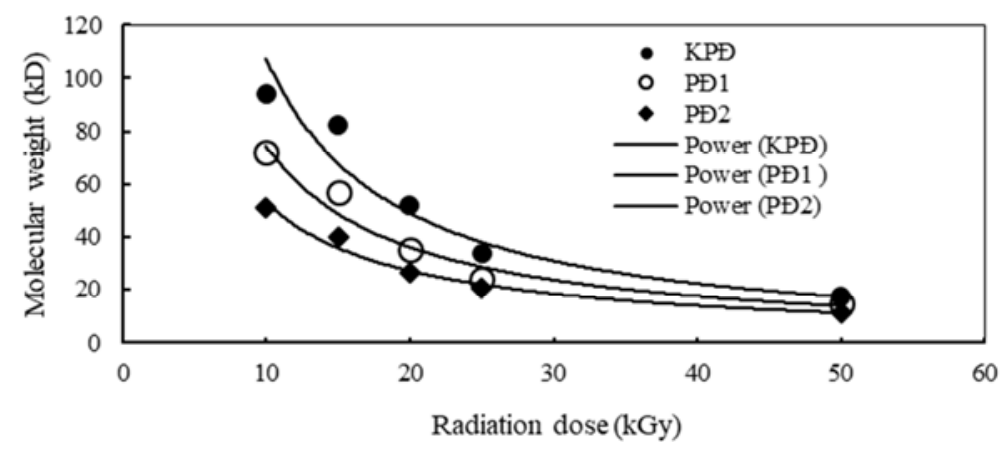

Note: KPĐ, PDD1, and PDD2 was the none-segment, $1^{\text {st }}$ segment, and $2^{\text {nd }}$ segment, respectively.

Figure 7. Changes in molecular weight of oligochitosan of segment 1 and 2 as affected by the radiation dose. 


\subsection{Antibacterial Activities}

The results showed that oligosaccharide chitosan from chitosan solution and chitosan flakes exhibited antibacterial activity on E. coli O157: H7, S. typhimurium, L. monocytogenes, S. aureus, and B. subtilis. Antibacterial activity of M1.1 (66 kGy) and M1.6 (166 kGy) was higher than in other samples. M1.3 (100 kGy) and M1.5 (158 kGy) were no resistance $E$. coli O157:H7 (Table 1). $L$. monocytogenes, $S$. aureus, and B. subtilis were impacted by oligosaccharide chitosan preparing at the different conditions of radiation. Oligosaccharide chitosan exhibited the highest antibacterial on Bacillus subtilis in comparison to other bacterial. $1^{\text {st }}, 2^{\text {nd }}$, and $3^{\text {rd }}$ segment of oligosaccharide chitosan were oxidation fast and decreased the activity to near zero.

Table 1. Impact of oligosaccharide chitosan concentration on the growth of bacteria.

\begin{tabular}{|c|c|c|c|c|c|}
\hline \multirow{2}{*}{ Sample } & \multicolumn{5}{|c|}{ Minimum inhibitory concentration } \\
\hline & E. coli 0157:H7 & S. typhimurium & L. monocytogenes & S. aureus & B. subtilis \\
\hline \multicolumn{6}{|c|}{ Oligosaccharide chitosan obtaining from the radiated chitosan solution } \\
\hline Oligosaccharide chitosan $10 \%$ & $1 / 8$ & $1 / 4$ & $1 / 4$ & $1 / 4$ & $1 / 8$ \\
\hline Oligosaccharide chitosan $5 \%$, pH 6.5 & $1 / 2$ & $1 / 2$ & $1 / 2$ & $1 / 2$ & $1 / 4$ \\
\hline \multicolumn{6}{|c|}{ Oligosaccharide chitosan obtaining from the radiated chitosan flakes ( $5 \%$ solution) } \\
\hline M1.1 (66kGy) & $1 / 8$ & $1 / 2$ & $1 / 8$ & $1 / 8$ & $1 / 16$ \\
\hline M1.3 (100kGy) & - & $1 / 2$ & $1 / 2$ & $1 / 8$ & $1 / 8$ \\
\hline M1.5 (158kGy) & - & $1 / 2$ & $1 / 2$ & $1 / 8$ & $1 / 8$ \\
\hline M1.6 (166kGy) & $1 / 8$ & $1 / 2$ & $1 / 8$ & $1 / 8$ & $1 / 16$ \\
\hline The control (non-radiation) & $1 / 4$ & - & $1 / 4$ & $1 / 4$ & $1 / 4$ \\
\hline
\end{tabular}

Table 2. The minimum inhibition concentration of oligosaccharide chitosan from radiated chitosan flakes on the bacteria growth.

\begin{tabular}{|c|c|c|c|c|c|}
\hline \multirow{2}{*}{ Sample } & \multicolumn{4}{|c|}{ Dilution factor } & \multirow{2}{*}{ Inhibition } \\
\hline & $1 / 2$ & $1 / 4$ & $1 / 8$ & $1 / 16$ & \\
\hline \multicolumn{6}{|l|}{ E. coli O157:H7 } \\
\hline M1.1 (66 kGy) & ++++ & ++++ & + & - & $1 / 4$ \\
\hline M1.6 (166 kGy) & ++++ & ++ & - & - & $1 / 2$ \\
\hline \multicolumn{6}{|c|}{ Salmonella typhimurium } \\
\hline M1.1 (66 kGy) & +++ & ++ & + & + & $1 / 2$ \\
\hline M1.6 (166 kGy) & +++ & + & + & + & $1 / 2$ \\
\hline \multicolumn{6}{|c|}{ Listeria monocytogenes } \\
\hline M1.1 (66 kGy) & ++++ & ++++ & ++++ & ++++ & $1 / 16$ \\
\hline M1.6 (166 kGy) & ++++ & ++++ & ++++ & ++++ & $1 / 16$ \\
\hline \multicolumn{6}{|c|}{ Staphylococcus aureus } \\
\hline M1.1 (66 kGy) & ++++ & ++++ & + & - & $1 / 4$ \\
\hline M1.6 (166 kGy) & ++++ & +++ & + & - & $1 / 4$ \\
\hline \multicolumn{6}{|l|}{ Bacillus subtilis } \\
\hline M1.1 (66 kGy) & ++++ & ++++ & ++++ & +++ & $1 / 16$ \\
\hline M1.6 (166 kGy) & ++++ & ++++ & ++++ & ++ & $1 / 8$ \\
\hline
\end{tabular}

At the lowest dilution ratio of 1/16 (v/v), M1.1 (66 kGy) $(++++)$ was the resistance of Listeria monocytogenes and Bacillus subtilis and M1.6 (166 kGy) was the resistance of Listeria monocytogenes (Table 2). At the dilution ratio of $1 / 8$ (v/v), M1.6 (166 kGy) resisted Bacillus subtilis. For Staphylococcus aureus, M1.1 (66 kGy) and M1.6 (166 kGy) exhibited resistance activity at the dilution ratio of $1 / 4(\mathrm{v} / \mathrm{v})$. M1.1 (66 kGy) and M1.6 (166 kGy) was the resistance of Salmonella typhimurium at the dilution ratio of $1 / 2(\mathrm{v} / \mathrm{v})$. For E. coli, M1.1 (66 kGy) and M1.6 (166 kGy) exhibited activity at the dilution ratio of $1 / 4$ and $1 / 2(\mathrm{v} / \mathrm{v})$, respectively. Therefore, the impact of oligosaccharide chitosan on Salmonella typhimurium was weak than other bacterial, and $E$. coli was affected by M1.6 (166 kGy) less than M1.1 (66 kGy).

The oligosaccharide chitosan from chitosan flakes possessed higher antibacterial activity than that from chitosan solution at the same concentration. The antibacterial activity of oligosaccharide chitosan at the radiation dose of $66 \mathrm{kG} \gamma$ was higher than that at the radiation dose. The oligosaccharide chitosan affected gram-negative bacteria more than gram-positive bacteria, and the highest impact on L. monocytogenes and B. subtilis, compared to other bacteria. The minimum inhibition concentration of oligosaccharide chitosan on L. monocytogenes and B. subtilis was $0.3125 \%$. For most other bacteria strains, the minimum inhibition concentration of oligosaccharide chitosan was in the range of 0.625 to $1.25 \%$. Numerous previous studies noticed on antibacterial activity of oligosaccharide chitosan, as in [15, 16]. Antibacterial activity of oligosaccharide chitosan depended on the molecular weight of oligosaccharide chitosan, the chitosan destroying method, and the material extracting of chitosan $[17,18]$. The difference caused the diverse on antibacterial activity of oligosaccharide chitosan. The antibacterial mechanism of oligosaccharide chitosan was to base on the membrane disruption [15], the inhibition of RNA and protein synthesis, the breakage of the intracellular 
component [16], the ionic interaction [19], and free amino groups of oligosaccharide chitosan [20]. According to [21], cationic formation based on the amino protonation leading the bacterial killing. All mechanisms had a common to be interaction with the cell membrane of bacterial and mechanism inhibition in microorganisms. Antimicrobial activity depended not only on the physical chemistry properties of chitosan and their derivatives, but also on the concentration of metal ions $\left(\mathrm{K}^{+}, \mathrm{Na}^{+}, \mathrm{Mg}^{2+}\right.$, and $\left.\mathrm{Ca}^{2+}\right)$ [22].
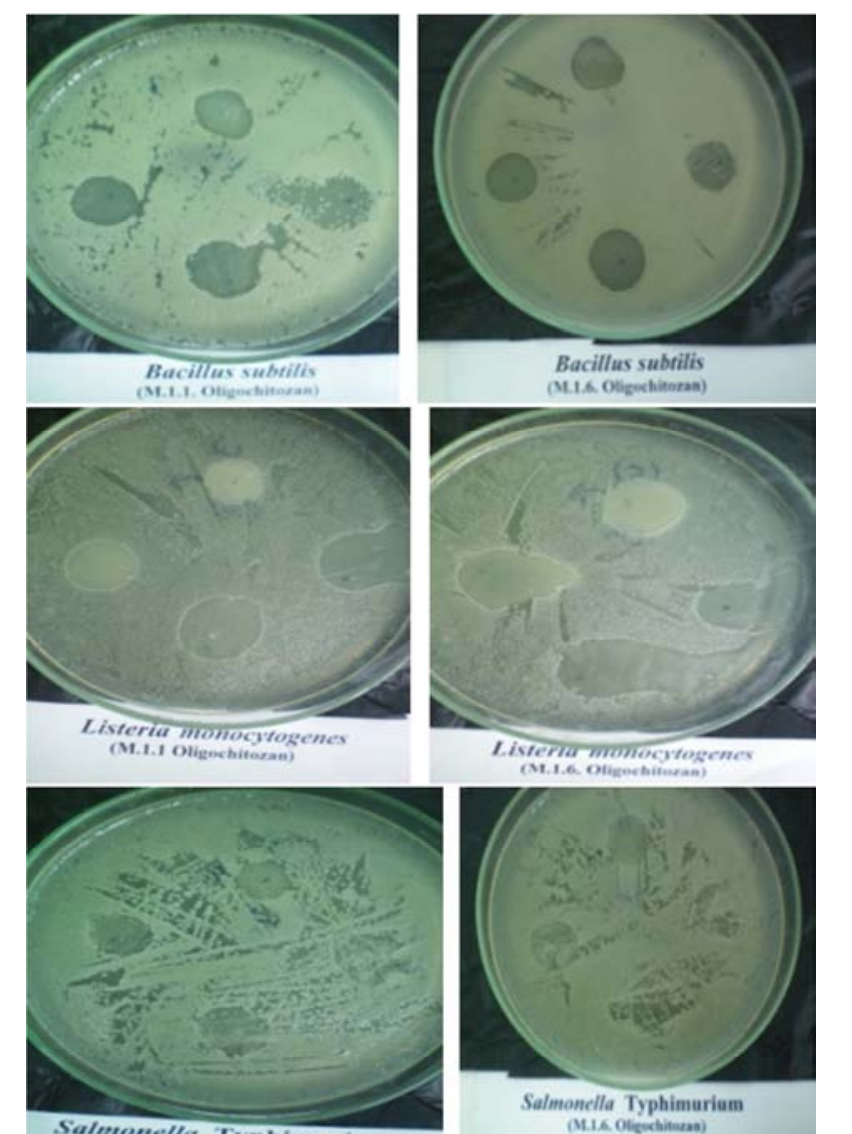

Lisferm womegrogenes
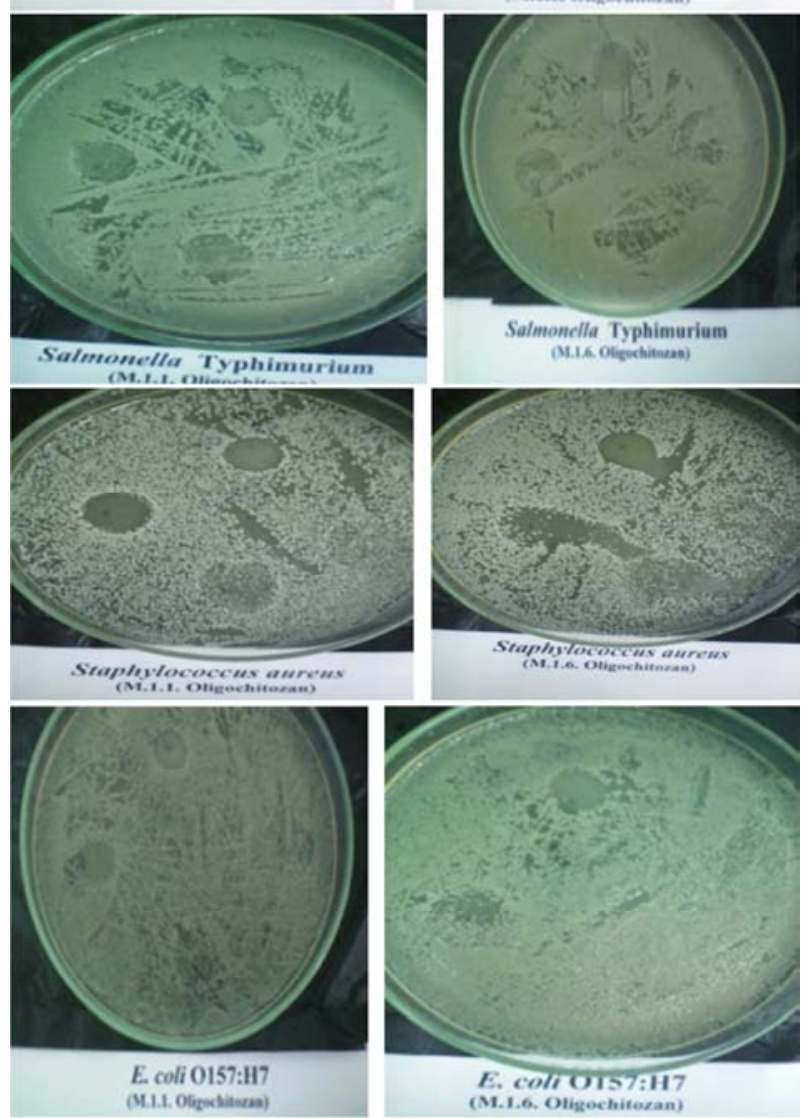

Figure 8. Some pictures of the antibacterial of oligosaccharide chitosan.

\section{Conclusion}

The $\gamma 60$ radiation destroyed chitosan to oligosaccharide chitosan that got the molecular weight under $100 \mathrm{kDa}$. The viscosity and the molecular weight of oligosaccharide chitosan were negative proportional to the radiation dose, positively proportional to the chitosan concentration. Acetone and the mixture of methanol and aqueous were useful in the segment of oligosaccharide chitosan. The average molecular weight of the $3^{\text {rd }}$ segment was under $11 \mathrm{kDa}$. Oligosaccharide chitosan produced by radiation of chitosan flakes (dried chitosan) had higher antibacterial activity than that of oligosaccharide chitosan produced by radiation of chitosan solution. The radiated oligosaccharide chitosan at the radiation dose of $66 \mathrm{kGy}$ had the highest antibacterial activity. Oligosaccharide chitosan at the radiation dose of $66 \mathrm{kGy}$ had antibacterial activity on all tested bacteria strains: E. coli O157: H7, Salmonella typhimurium, L. monocytogenes, S. aureus, and $B$. subtilis. Antibacterial activity on bacteria gram (-) was higher than bacteria gram $(+)$, in particular, the antibacterial activity was observed on L. monocytogenes and B. subtilis, which are most common spoilage bacteria on the food system. Oligosaccharide chitosan at the concentration of $0.3125 \%$ inhibited L. monocytogenes and B. subtilis.

\section{Acknowledgements}

The authors thank the funding from the Vietnam Ministry of Science and Technology and the helping of Nha Trang University, Nuclear Research Institute, Industrial University of Ho Chi Minh City, and Nhatrang Institute of Technology Application and Research.

\section{References}

[1] Yongjae L., Hyun-Wook, K. and Yuan, H. B. K. (2018). New route of chitosan extraction from blue crabs and shrimp shells as flocculants on soybean solutes. Food Sci Biotechnol, 27 (2): 461-466.

[2] Thirunavukkarasu N. and Shanmugam, A. (2009). Extraction of chitin and chitosan from Mud crab scylla tranquebarica (fabricius, 1798). Int J Applied Bioeng, 4 (2): 31-33.

[3] Dang X. D. and Bui, X. V. (2019). Study on preparation of water-soluble chitosan with varying molecular weights and its antioxidant activity. Adv Mater Sci Eng (Special): 1-8.

[4] Bing Y., Lu Li, Congxia, X., Kun, L. and Shitao, Y. (2014). Preparation of oligochitosan via In situ enzymatic hydrolysis of chitosan by amylase in [Gly] BF4 ionic liquid/water homogeneous system. J Appl Polym Sci, 131 (23): 1-9.

[5] Shuang L., Yaxuan, S. and Xueling, D. (2018). A review of the preparation, analysis and biological functions of chitooligosaccharide. Int J Mol Sci, 19 (8): 2197.

[6] Nguyen N. D., Dang, V. P., Nguyen, T. A. and Nguyen, Q. H. (2011). Synergistic degradation to prepare oligochitosan by $\gamma$-irradiation of chitosan solution in the presence of hydrogen peroxide. Radiat Phys Chem, 80 (7): 848-853. 
[7] Andrew J. (2001). Determination of minimum inhibitory concentrations. J Antimicrob Chemother, 48 (S1): 5-16.

[8] Duy N. N., Phu, D. V., Anh, N. T. and Hien, N. Q. (2011). Synergistic degradation to prepare oligochitosan by $\gamma$-irradiation of chitosan solution in the presence of hydrogen peroxide. Radiat Phys Chem, 80 848-853.

[9] Alburquenque C., Bucarey, S., Neira-Carrillo, A., Urzúa, B., Hermosilla, G. and Tapia, C. (2010). Antifungal activity of low molecular weight chitosan against clinical isolates of Candida spp. Med Mycol, 48 (8): 1018-1023.

[10] Hai L., Diep, T. B., Naotsugu, N., Fumio, Y. and Tamikazu, K. (2003). Radiation depolymerization of chitosan to prepare oligomers. Nucl Instrum Methods Phys Res B, 208 466-470.

[11] Czechowska-Biskup R., Wach, R., Rosiak, J. and Ulański, P. (2018). Progress on Chemistry and Application of Chitin and its Derivatives. Progress on chemistry and application of chitin and its derivatives. Poland. XXIII.

[12] Naoual J., Abdelaziz, B. and Mohammed, B. (2011). Probiotic Potential of Lactobacillus trains isolated from known popular traditonal Moroccan dairy products. Br Microbiol Res $J, 1$ (4): 79-94.

[13] Seyfarth F., Schliemann, S., Elsner, P. and Hipler, U. (2008). Antifungal effect of high- and low-molecular-weight chitosan hydrochloride, carboxymethyl chitosan, chitosan oligosaccharide and N-acetyl-D-glucosamine against Candida albicans, Candida krusei and Candida glabrata. Int J Pharm, 353 (1-2): 139-148.

[14] Ulanski P. and Rosiak, J. (1992). Preliminary study on radiation-induced changes in chitosan. Radiat Phys Chem, 39 53-57.
[15] Hiroaki S., et al. (2019). Antibacterial activity of lysozyme-chitosan oligosaccharide conjugates (LYZOX) against Pseudomonas aeruginosa, Acinetobacter baumannii and Methicillin-resistant Staphylococcus aureus. PLoS One, 14 (5): e0217504.

[16] Suyeon K. (2018). Competitive biological activities of chitosan and its derivatives: Antimicrobial, antioxidant, anticancer, and anti-inflammatory activities. Int J Polym Sci 1-13.

[17] Suphavadee C. (2018). Antibacterial activity of chito-oligosaccharides (COSS) from shrimp shells wastes. $A d v$ Plants Agric Res, 8 (6): 392-394.

[18] Zivanovic S., Basurto, C., Chi, S., Davidson, P. and Weiss, J. (2004). Molecular weight of chitosan influences antimicrobial activity in oil-in-water emulsions. J Food Prot, 67 (5): 952-959.

[19] Jeon S., Oh, M., Yeo, W.-S., Galvão, K. and Jeong, K. (2014). Underlying mechanism of antimicrobial activity of chitosan microparticles and implications for the treatment of infectious diseases. PLoS ONE, 9 (3): e92723.

[20] Andres Y., Giraud, L., Gerente, C. and Cloirec, P. L. (2007). Antibacterial effects of chitosan powder: Mechanisms of action. Environ Technol, 28 (12): 1357-1363.

[21] Jianhui L., Yiguang, W. and Liqing, Z. (2016). Antibacterial activity and mechanism of chitosan with ultra high molecular weight. Carbohydr Polym, 148 (5): 200-205.

[22] Chen W., Wu, Q., Zhang, J. and Wu, H. (2008). Antibacterial mechanism of chitosan. Wei Sheng Wu Xue Bao, 48 (2): 164-168. 